\title{
Synthesis of a Novel Cytokine and Its Gene (LD78) Expressions in Hematopoietic Fresh Tumor Cells and Cell Lines
}

\author{
Yuji Yamamura, ${ }^{*}$ Toshio Hattori, ${ }^{*}$ Kenshi Obaru, ${ }^{\star}$ Kenji Sakai, ${ }^{*}$ Norio Asou, ${ }^{*}$ Kiyoshi Takatsuki, \\ Yasukazu Ohmoto, ${ }^{\ddagger}$ Hisayuki Nomiyama, ${ }^{\S}$ and Kazunori Shimada ${ }^{\S}$ \\ ${ }^{*}$ Second Department of Internal Medicine and ${ }^{\S}$ Department of Biochemistry, Kumamoto University Medical School, \\ Kumamoto 860, Japan; and ${ }^{\ddagger}$ Research Institute of Otsuka Pharmaceutical Company, Tokushima 771-01, Japan
}

\begin{abstract}
The gene coding for the protein LD78 was isolated from stimulated human tonsillar lymphocytes by differential hybridization. The gene product consisted of 92 amino acids with characteristics of cytokines. LD78 gene transcripts were detected in eight of eight fresh samples of cells from patients with acute nonlymphocytic leukemia (ANLL) by Northern blot analysis. ANLL cells with monocytic features gave the strongest bands. RNA transcripts were found in two of three samples of cells from patients with adult $T$ cell leukemia (ATL), eight of nine samples from patients with acute lymphocytic leukemia (ALL) of $B$ cell lineage, and one of the three samples from patients with T cell ALL. KG-1, HL-60, HUT 102, MT-2, and MJ cell lines expressed the LD78 gene constitutively. The LD78 protein was detected in culture supernatants and cell lysates of HUT 102, MT-2, MJ, and fresh ATL cells by Western blot analysis. This protein was not found in culture supernatants or cell lysates of monocytic leukemia cells and HL-60 cells, although LD78 transcripts were found in those cells. The discrepancy between gene and protein expression might be explained by the stability of the mRNA.

Thus, the protein may be involved in the neoplastic transformation of hematopoietic cells.
\end{abstract}

\section{Introduction}

A cDNA named pLD78 has been isolated from a library constructed of poly $(\mathrm{A})^{+}$RNAs of human tonsillar lymphocytes stimulated with the tumor promoter phorbol 12-myristate 13acetate (PMA) and PHA by differential hybridization (1). The cDNA encodes a protein, LD78, of 92 amino acids including a putative signal sequence of 22 amino acids. Northern blot analysis showed that the expression of the LD78 gene in such lymphocytes increases 10 -fold when stimulated by either PMA or PHA, and 30-fold when stimulated by both. By sequence analysis of the LD78 gene isolated from a human gene library, the 5 ' flanking regions of this gene were found to have homology with the corresponding regions of the human IL-2 and $\gamma$-IFN genes. These findings suggest that LD78 encodes a

Address reprint requests to Dr. Yuji Yamamura, Second Department of Internal Medicine, Kumamoto University Medical School, 1-1-1 Honjo, Kumamoto 860, Japan.

Received for publication 22 December 1988 and in revised form 27 July 1989

J. Clin. Invest.

(c) The American Society for Clinical Investigation, Inc.

0021-9738/89/12/1707/06 \$2.00

Volume 84, December 1989, 1707-1712 novel cytokine with an unknown functional role. In a computer search of a protein sequence database several proteins in the $\beta$-thromboglobulin $(\beta \text {-TG })^{1}$ superfamily have been found to have sequences similar to that of the LD78 protein (2). Among the members of the superfamily there is a mouse protein named TCA 3 inducible in inducer T cells by mitogens or antigens (3); human platelet basic protein (4), a precursor of connective tissue activating peptide III (5) and $\beta$-TG (6); the human growth-regulated protein expressed at moderate levels in the highly tumorigenic cells (7), and related to the melanoma growth stimulatory activity (MGSA; $)$ ); a product named IP10 of U937 cells stimulated with $\gamma$-IFN which have monocytic characteristics (9); platelet factor 4 released from platelet $\alpha$-granules during platelet aggregation (10); a protein (9E3) expressed at a high level in chicken embryonal fibroblasts transformed with Rous sarcoma virus (11); and a mouse neutrophil-activating factor inducible in monocytes by a mitogen (12). $\beta$-TG, the function of which has not been identified, is secreted from platelet granules. It may be a final product of connective tissue activating peptide III, which stimulates DNA and glycosaminoglycan synthesis and seems to be involved in inflammation (5). Other protein sequences homologous to the sequences of LD78, such as growth-regulated protein/MGSA and 9E3, may be involved in tumorigenesis $(7,8$, 11). MGSA is secreted by melanoma cells and stimulates the growth of a wide variety of other cells, as well as melanoma cells (8).

To identify the biological properties of LD78 we studied the expression of the LD78 gene and synthesis of the product by hematopoietic tumor cells obtained from leukemia patients by Northern and Western blot analysis. We are interested in the functional role(s) of the LD78 protein and those of other proteins with homologous sequences.

\section{Methods}

Enzymes and chemicals. Restriction endonucleases and mung bean nuclease were obtained from Takara Shuzo Co., Kyoto, Japan, and DNA polymerase Klenow fragment was from Toyobo Co., Osaka, Japan. Guanidinium thiocyanate was obtained from Fluka Chemie AG, Hauppage, NY, and $\left[\alpha-{ }^{32} \mathrm{P}\right] \mathrm{dCTP}(3,000 \mathrm{Ci} / \mathrm{mmol})$ was from Amersham Japan, Tokyo, Japan.

Patients. 6 patients with adult T cell leukemia (ATL) caused by human $\mathrm{T}$ cell lymphotropic virus type $1(\mathrm{HTLV}-1), 12$ patients with

1. Abbreviations used in this paper: ACT, actinomycin D; ALL, acute lymphocytic leukemia; ANLL, acute non-lymphocytic leukemia; ATL, adult T cell leukemia; CHX, cycloheximide; HTLV-1, human T cell lymphotropic virus type 1; MGSA, melanoma growth stimulatory activity; MIP, macrophage inflammatory protein; T-ALL, T cell ALL; $\beta$-TG, $\beta$-thromboglobulin. 
acute lymphocytic leukemia (ALL), and 8 patients with acute nonlymphocytic leukemia (ANLL) were examined. ATL is well known to be $T$ cell leukemia caused by HTLV-1 infection, and ATL cells express mature and activated T cell antigen (13). Three of six ATL patients were in the acute phase and others were chronic based on their clinical profiles (13). 3 of the 12 ALL patients were diagnosed as having T cell ALL (T-ALL) and the others were diagnosed as having B cell lineage ALL according to their phenotypes and genotypes (14). The eight patients with ANLL were diagnosed by use of the French-AmericanBritish classification $(15,16)$.

Cells and cell culture. Leukemic cells were separated from heparinized peripheral blood obtained from all patients by Ficoll-Conray density gradient sedimentation. The percentages of blasts exceeded $80 \%$ by the results of examination of cytocentrifuged preparations stained with May-Giemsa stain.

The cell lines used were T cell lines infected with HTLV-1: HUT 102, MT-2, MJ, and SKT-1 B (17) with activated T cell features. Also, mature or immature T cell lines HPB-MLT and HPB-ALL were used, as were cell lines with nonlymphocytic features (KG-1, HL-60, K562, and U937). These cells were cultured in RPMI 1640 medium (Nissui, Tokyo, Japan) supplemented with $10 \%$ heat-inactivated FCS (Gibco Laboratories, Grand Island, NY), $2 \mathrm{mM}$ L-glutamine, $100 \mathrm{U} / \mathrm{ml}$ penicillin, and $100 \mu \mathrm{g} / \mathrm{ml}$ streptomycin.

U937 cells were activated with LPS (Difco Laboratories Inc., Detroit, MI) at a concentration of $10 \mu \mathrm{g} / \mathrm{ml}$ and PMA (Consolidated Midland, Brewster, NY) at $10^{-8} \mathrm{M}$, and were harvested at $2,6,12$, or $24 \mathrm{~h}$ of culture.

To find whether the LD78 protein was glycosylated, MJ cells were cultured in the presence or absence of $5 \mu \mathrm{g} / \mathrm{ml}$ tunicamycin (Sigma Chemical Co., St. Louis, MO) for $24 \mathrm{~h}$ and analyzed by Western blot analysis.

For the assessment of the stability of LD78 mRNA, cycloheximide $(\mathrm{CHX} ; 10 \mu \mathrm{g} / \mathrm{ml}$ ) and actinomycin D (ACT; $5 \mu \mathrm{g} / \mathrm{ml}$ ) were added to cultures of $\mathrm{MJ}$ or HL-60 cells at the concentrations indicated in the figure legends.

Northern blot analysis. Total cellular RNA was extracted from the cells by the guanidinium thiocyanate method (18) and $10 \mu \mathrm{g}$ of RNA was applied to each lane. Northern blot analysis was done as described elsewhere (19). LD78 mRNA was detected by use of a 0.3-kb Xho I-Hind III fragment of LD78 cDNA (1) and labeled with a sp act of $10^{-9} \mathrm{cpm} / \mu \mathrm{g}$ with oligonucleotide primers and $\left[\alpha^{32} \mathrm{P}\right] \mathrm{dCTP}$ as previously described (20). IL-1 $\beta$ mRNA was detected with a $0.45-\mathrm{kb}$ Fok I-Pvu II fragment of IL- $1 \beta$ cDNA as described before (21). The chicken $\beta$-actin probe was purchased from Oncor Inc., Gaithersburg, MD. Hybridization was done by immersion of the membranes in a solution at $42^{\circ} \mathrm{C}$ of $50 \%$ formamide, $5 \times$ standard saline citrate (SSC), $20 \mathrm{mM}$ sodium phosphate buffer, $200 \mu \mathrm{g} / \mathrm{ml}$ denatured salmon sperm DNA, and $1 \times$ Denhardt's solution containing the radiolabeled probes. After hybridization for $10-18 \mathrm{~h}$ the filters were washed three times with $2 \times$ SSC and $0.1 \%$ SDS at room temperature, and once with $0.1 \times$ SSC and $0.1 \%$ SDS at $56^{\circ} \mathrm{C}$. The blots were then dried and used to expose $\mathrm{x}$-ray film at $-80^{\circ} \mathrm{C}$.

Construction of the plasmid ptrpIL-2-LD78. An LD78 cDNA insert $(0.8 \mathrm{~kb})$ was isolated from the plasmid pLD78 with Pst I and Pvu II and digested with Sfa NI. A DNA fragment of $564 \mathrm{bp}$ was isolated, treated with mung bean nuclease, and attached to a synthetic linker (5'CGATAATGGC $\mathrm{OH}^{3}$ and 5'pGCCATTAT $\mathrm{OH} 3$ ') followed by digestion with Cla I and Hind III. The DNA fragment was inserted between the Cla I and Hind III sites of the plasmid pTM1, which has a tryptophan promoter. The constructed plasmid was named ptrpLD78. Cells of Escherichia coli carrying the plasmid were disrupted with use of glass beads and the proteins obtained were separated by $15 \%$ SDS-PAGE and stained with Coomassie blue. A band corresponding to the LD78 protein was not found. Therefore, the plasmid ptrpLD78 was cleaved with Cla I, treated with DNA polymerase I (Klenow fragment), and digested with Hind III. The DNA fragment of $0.25 \mathrm{~kb}$ containing the LD78 cDNA was isolated and inserted between the Xba I and Hind III sites of ptrpIL-2-D8, which expressed human IL-2 under regulation by the tryptophan promoter in $E$. coli. The plasmid obtained was named ptrpIL-2-LD78 (Fig. 1). E. coli carrying this plasmid produced a fused protein, IL-2-LD78, composed of LD78 and the amino-terminal region of IL-2, and detected as described above.

$E$. coli cells carrying recombinant DNAs were propagated in accordance with the guidelines for recombinant DNA research issued by the Ministry of Education, Science, and Culture, Japan.

Preparation of rabbit anti-LD78 antibody OCT801. Male New Zealand albino rabbits were immunized subcutaneously seven times with 2-wk intervals with $100 \mu \mathrm{g}$ of IL-2-LD78 emulsified in $0.5 \mathrm{ml}$ of complete Freund's adjuvant. 6-7 d after the last immunization blood was collected from the rabbits and serum was obtained and stored at $-80^{\circ} \mathrm{C}$. The antisera were passed through an affinity column of IL-2 and the protein derived from $E$. coli coupled to $\mathrm{CNBr}$-Sepharose 4B (Pharmacia Fine Chemicals, Piscataway, NJ) to remove antibodies to the IL-2 and the protein. Western blot analysis showed that the antisera bound LD78 protein specifically. The specific antibody obtained was named OCT801.

Detection of LD78 protein by Western blot analysis. Cell lysates from human leukemic cells were obtained by incubation of $1 \times 10^{6}$ cells with $200 \mu$ l of lysis buffer (10\% glycerol, 5\% 2-mercaptoethanol, $2.3 \%$ SDS, $0.0625 \mathrm{M}$ Tris- $\mathrm{HCl}$, and $0.05 \%$ bromophenol blue) at $100^{\circ} \mathrm{C}$ for $5 \mathrm{~min}$. Cell supernatants were concentrated 10-fold with a microconcentrator (Centricon-10; Amicon Corp., Danvers, MA) and incubated with the same volume of the lysis buffer at $100^{\circ} \mathrm{C}$ for $5 \mathrm{~min}$. $20 \mu \mathrm{l}$ of the cell lysate or the cell supernatant was put in each well of the $15 \%$ SDS gel for PAGE. The separated proteins were then electrophoretically transferred from gels to a nitrocellulose membrane at room temperature in a $1-\mathrm{h}$ process. The nitrocellulose membrane was soaked in PBS containing $1 \%$ skim milk at $4^{\circ} \mathrm{C}$ for $1 \mathrm{~h}$ to prevent the nonspecific binding of proteins. The membrane was incubated for $16 \mathrm{~h}$ at $23^{\circ} \mathrm{C}$ with the antibody OCT801, which was diluted 1:500 (10-20 $\mathrm{mg} / \mathrm{ml}$ ) in PBS containing $0.1 \%$ BSA and $0.05 \%$ thimerosal. Bound polyclonal antibodies were made visible by incubation for $4 \mathrm{~h}$ with anti-rabbit IgG conjugated with horseradish peroxidase (Bio-Rad Laboratories, Richmond, CA) diluted 1:1,000 in PBS containing $0.1 \%$ BSA. After being washed, the membrane was incubated for $15 \mathrm{~min}$ with 4-chloro-1-naphthol $(0.6 \mathrm{mg} / \mathrm{ml}$ in PBS containing $20 \%$ ethanol and $0.018 \% \mathrm{H}_{2} \mathrm{O}_{2}$ ), rinsed with water, and dried. The supernatant from a 3-d culture of COS- 1 cells transfected by the DEAE-dextran method (22), with pcD-LD78 ${ }^{2}$ that encodes the LD78 protein, was used as a positive control. The molecular weight markers used were prestained SDS-PAGE standards (Bio-Rad Laboratories) and a kit for calibration of the molecular weight of polypeptides by electrophoresis calibration (Pharmacia Fine Chemicals).

\section{Results}

Detection of $L D 78 m R N A$. To examine the effect of LD78 gene products in causing tumorigenesis of hematopoietic cells, the expression of the LD78 gene in fresh leukemia cells and cell lines was examined by Northern blot analysis (Table I). Representative results are shown in Figs. 2 and 3. Clinical profiles of the patients who provided samples with results given in this report are described in Table II. Two of the patients with ATL were in the acute phase. The third ATL patient had high leukemic counts in the peripheral blood but was clinically stable without treatment, and thus was categorized as having chronic ATL (13). LD78 mRNA $~ 0.9 \mathrm{~kb}$ long was detected in two of the two samples of ATL cells from patients in the acute phase (Fig. 2, lanes 5 and 6) and in eight of the

2. LD78 cDNA was ligated with pcDE, a modified Okayama-Berg cDNA expression plasmid, digested with Eco RI. The plasmid obtained was termed pcD-LD78. 


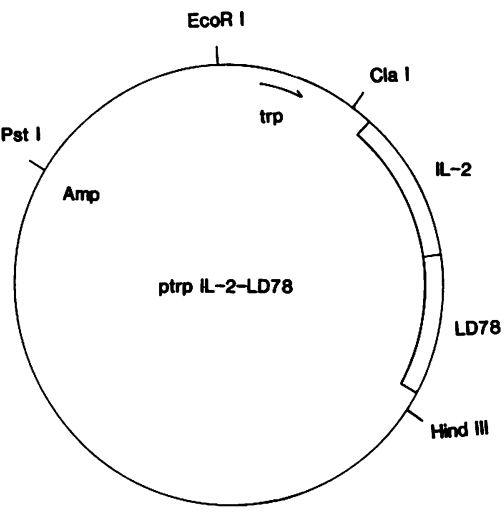

Figure 1. Structure of ptrpIL-2-LD78. The construction is described in Methods.

eight samples of ANLL cells (Fig. 3, lanes 5-12), but not in two of the three samples from patients with T-ALL (Fig. 2, lane 10) or in the sample from a patient with chronic ATL (Fig. 2, lane 7). The gene transcripts were found in eight of the nine samples from patients with B cell lineage ALL (data not shown).

mRNA of the same size was found in HUT 102, MT-2, and MJ (HTLV-1-infected T cell lines with activated $\mathrm{T}$ cell features), but HPB-MLT and HPB-ALL, with features of immature or mature $T$ cells, did not express the gene (Fig. 2). One cell line infected with HTLV-1 (SKT-1B) did not express the gene. Expression of the gene was detected in KG-1 and HL-60, but not in K562 or U937 (Fig. 3). Levels of LD78 mRNA expression were higher in the ANLL cells than in fresh ATL cells. The strongest band was observed for RNA from fresh cells with monocytic features (Fig. 3, lanes 7 and 8 ).

Table I. Expression of LD78 $\mathrm{mRNA}$ and LD78 Protein in Fresh Leukemia Cells and in Cell Lines Detected by Northern and Western Blot Analysis

\begin{tabular}{|c|c|c|c|}
\hline \multirow[b]{2}{*}{ Cell } & \multirow[b]{2}{*}{ mRNA detected } & \multicolumn{2}{|c|}{ Protein detected } \\
\hline & & Cell lysate & $\begin{array}{c}\text { Culture } \\
\text { supernatant }\end{array}$ \\
\hline \multicolumn{4}{|l|}{ Fresh leukemia cells } \\
\hline ATL & $2 / 3^{*}$ & $2 / 4$ & $2 / 4$ \\
\hline B cell lineage ALL & $8 / 9$ & $0 / 2$ & $0 / 2$ \\
\hline T-ALL & $1 / 3$ & $0 / 1$ & $0 / 1$ \\
\hline ANLL & $8 / 8$ & $0 / 2$ & $0 / 2$ \\
\hline \multicolumn{4}{|l|}{ Cell lines } \\
\hline \multicolumn{4}{|c|}{ HTLV-1-infected T cells } \\
\hline HUT 102 & + & + & + \\
\hline MT-2 & + & + & + \\
\hline MJ & + & + & + \\
\hline SKT-1B & - & $\mathrm{ND}^{\ddagger}$ & ND \\
\hline \multicolumn{4}{|l|}{$\mathrm{T}$ cells } \\
\hline HPB-MLT & - & ND & ND \\
\hline HPB-ALL & - & - & - \\
\hline \multicolumn{4}{|c|}{ Nonlymphocytic cells } \\
\hline KG-1 & + & - & - \\
\hline HL-60 & + & - & - \\
\hline K562 & - & ND & ND \\
\hline U937 & - & ND & ND \\
\hline
\end{tabular}

* No. of positive cases/number of tested cases. ${ }^{\ddagger} \mathrm{ND}$, not done.
Kinetics of LD78 mRNA expression after LPS and PMA treatment of U937 cells. LD78 mRNA was produced by myelocytic and monocytic cells as well as by activated $\mathrm{T}$ cell lines, and the LD78 protein has sequences homologous with those of other proteins that may be involved in tumorigenesis and inflammation. The kinetics of the expression of the LD78 gene in U937 cells stimulated with LPS and PMA were compared with those of the IL- $1 \beta$ gene, because IL- $1 \beta$ is also involved in these phenomena. LD78 mRNA was detected $2 \mathrm{~h}$ after stimulation began, reached a peak level by $12 \mathrm{~h}$, and was present at a lower level at $24 \mathrm{~h}$ (Fig. $4 \mathrm{~A}$ ). The kinetics of expression of IL-1 $\beta$ were similar (Fig. $4 B$ ).

Detection of $L D 78$ protein. Potential features of cytokine, LD78 gene structures, and the similarity of the kinetics of LD78 gene expression with IL-1 $\beta$ suggested that the protein coded by the LD78 gene might be secreted. Western blot analysis with the specific antibody OCT801 was used to study the production and secretion of the LD78 protein. The specificity of the antibody by Western blot analysis is shown in Fig. 5 . The antibody reacted only with the IL-2-LD78 protein (lane 2); it bound the LD78 protein specifically. The antibody was usually diluted 1:500, but it was not reactive with IL-2 even when diluted only 1:100 (data not shown).

The samples from cell lysates and cell supernatants of some fresh leukemia cells and cell lines were examined (Table I). The LD78 protein $(\sim 7.8 \mathrm{kD})$ was detected in two of the four lysates of cells from patients with ATL, but not in any lysates of the ANLL or ALL cells. Protein of the same size was found in HUT 102, MT-2, and MJ, but not in KG-1, HL-60, or HPB-ALL. The highest concentration of protein was in the MJ cells. There were bands in the same places with the supernatants. Representative results are shown in Fig. 6.

To elucidate the reason for the lack of LD78 protein, despite the expression of LD78 gene in HL-60 cells, HL-60 cells were stimulated with LPS and PMA for $2 \mathrm{~d}$. A high amount of LD78 mRNA was induced in stimulated HL-60 cells and we could detect the LD78 protein in culture supernatants as well as in cell lysates of stimulated HL-60 cells (data not shown). These findings strongly suggested that the lack of LD78 protein could be explained by a low mRNA level, but other possibilities could not be ruled out.

When MJ cells were cultured with or without tunicamycin, the molecular weight of the LD78 protein produced by the cells with the two treatments was the same (data not shown), suggesting that the LD78 protein was not $N$-glycosylated, consistent with the observation that there is no $\mathrm{N}$-glycosylation site (Asp-X-Thr/Ser) in the amino acid sequence of the LD78 protein (1). There may be $O$-glycosylation present.

Regulation of LD78 gene expression. LD78 mRNA was expressed in monocytic leukemia cells and HL-60 (Fig. 3, lanes 2 and 8 ), but LD78 proteins were not found in culture supernatants or lysates of these cells (Fig. 6, lanes 4, 5, 9, and 10). To explore this discrepancy we studied the regulation of LD78 mRNA expression in two cell lines, MJ and HL-60. MJ cells expressed both LD78 mRNA and protein, but HL-60 cells expressed only mRNA. HL-60 cells were exposed to CHX, ACT, or a combination of these agents for 1,3 , or $6 \mathrm{~h}$. In HL-60 cells LD78 mRNA almost completely disappeared by $3 \mathrm{~h}$ with ACT alone, and mRNA degradation was not completely inhibited by $\mathrm{CHX}$ (Fig. $7 \mathrm{~B}$ ), suggesting that the LD78 mRNA was labile. On the other hand, the mRNA of MJ cells did not decrease during $6 \mathrm{~h}$ with ACT alone. With a combina- 


\section{$\begin{array}{lllllllllll}1 & 2 & 3 & 4 & 5 & 6 & 7 & 8 & 9 & 10\end{array}$}

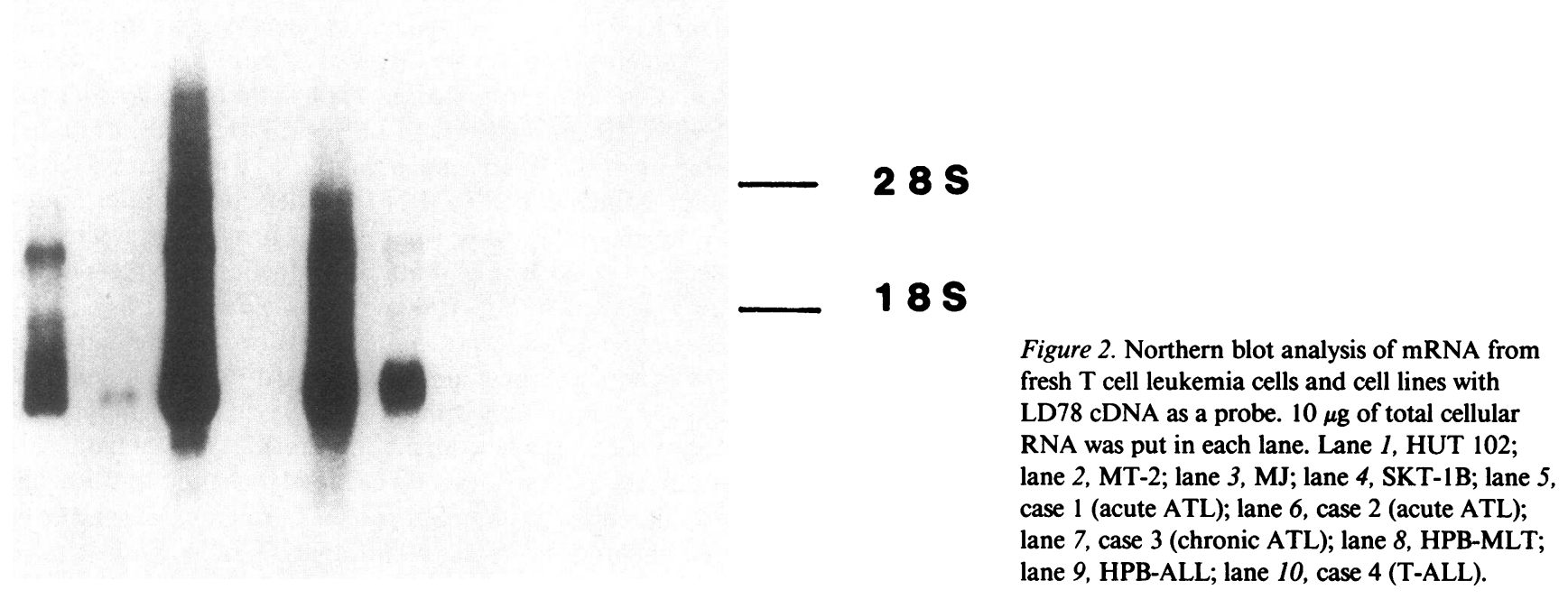

tion of the two, or with $\mathrm{CHX}$ alone, the level of mRNA increased slightly (Fig. $7 \mathrm{~A}$ ). These results indicate that mRNA in MJ cells was more stable than that in HL-60 cells. Additionally, total RNA but not poly(A) ${ }^{+}$RNA were used throughout the experiments, but the intensities of the bands given by a chicken $\beta$-actin probe were almost the same (Fig. 7). Therefore, it was confirmed that comparable amounts of RNA were applied to each lane.

\section{Discussion}

We examined the expression of the LD78 gene in primary hematopoietic leukemia cells and cell lines. The gene was expressed in the various leukemia cells. All ANLL cells, eight of the nine samples of B cell lineage ALL cells, and two of the three samples of ATL cells expressed the gene. The intensities

$\begin{array}{lllllllllllll}1 & 2 & 3 & 4 & 5 & 6 & 7 & 8 & 9 & 10 & 11 & 12 & 13\end{array}$

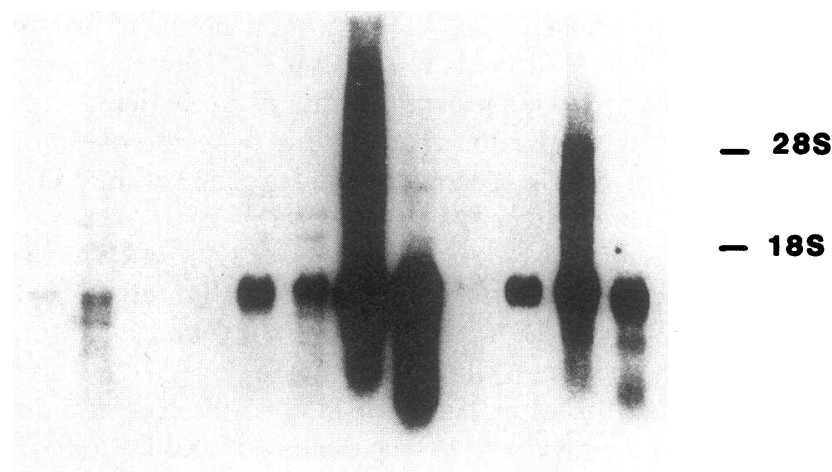

Figure 3. Northern blot analysis of mRNA from fresh nonlymphocytic leukemia cells and cell lines with LD78 cDNA as a probe. $10 \mu \mathrm{g}$ of total cellular RNA was put in each lane. Lane 1, KG-1; lane 2, HL-60; lane 3, K562; lane 4, U937; lane 5, case 5 (M1); lane 6, case 6 (M1); lane 7, case 7 (M5b); lane 8, case 8 (M5a); lane 9, case 9 (M4); lane 10, case 10 (M7); lane 11, case $11(\mathrm{M} 7)$; lane 12, case 12 (M7); lane 13, HPB-MLT (negative control). of the bands in Northern blot assays of ANLL cells were stronger than those of ATL and B cell lineage ALL cells. The monocytic leukemia cells gave the strongest bands. The findings were very similar when cell lines were used. Two of the four nonlymphocytic cell lines expressed the gene, and stimulation of U937 cells with LPS and PMA induced the gene. Thus, the LD78 gene was expressed not only in activated T cells but also in myelocytic and monocytic cells. The abundant expression of the LD78 gene in monocytic leukemia cells suggested that the main producers of the LD78 gene are monocytes.

The LD78 protein resembles cytokines because it has putative signal sequences and because the $5^{\prime}$ flanking regions of the LD78 gene have homology with those of IL-2 and $\gamma$-IFN (1). Thus, we examined whether the LD78 protein secreted by use of specific antibody against LD78 protein in Western blot assays. The 7.8-kD LD78 protein was detected in culture supernatants as well as in cell lysates. The size of the protein in both kinds of preparations was about the same.

Table II. Clinical Profiles of Patients

\begin{tabular}{rrllr}
\hline Case & Age & Sex & \multicolumn{1}{c}{ Diagnosis } & White blood cells \\
\hline & & & & $10^{\circ} /$ liter \\
1 & 40 & M & Acute ATL & 34.5 \\
2 & 59 & F & Acute ATL & 45.2 \\
3 & 45 & F & Chronic ATL & 28.3 \\
4 & 12 & M & T-ALL & 203.4 \\
5 & 60 & M & ANLL (M1) & 236.0 \\
6 & 59 & F & (M1) & 91.0 \\
7 & 51 & F & (M5b) & 88.6 \\
8 & 84 & F & (M5a) & 215.6 \\
9 & 80 & M & (M4) & 187.0 \\
10 & 51 & M & (M7) & 2.3 \\
11 & 56 & F & (M7) & 2.8 \\
12 & 60 & F & (M7) & 52.4 \\
& & & & \\
\hline
\end{tabular}




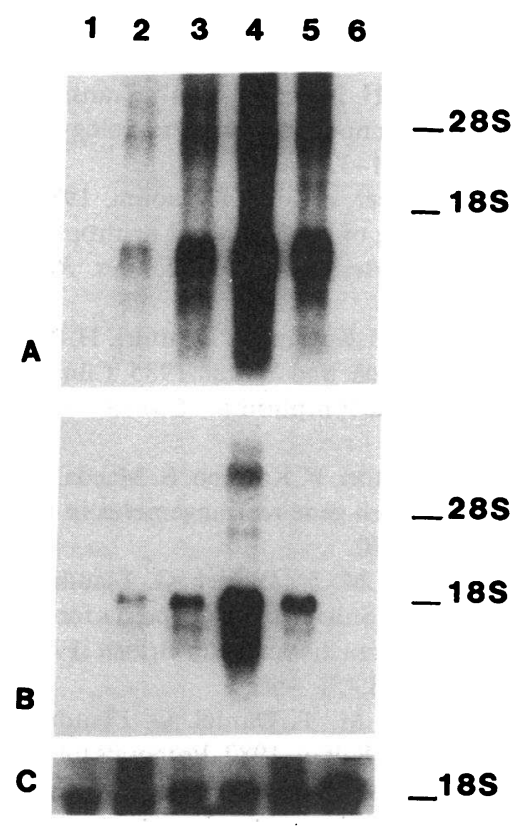

1

Figure 4. Kinetics of LD78 mRNA induction after LPS and PMA treatment of U937 cells. $10 \mu \mathrm{g}$ of total cellular RNA from U937 cells stimulated with LPS and PMA and harvested $0,2,6,12$, or 24 $\mathrm{h}$ later (lanes 1-5) was blotted and hybridized to $\operatorname{LD78}(A)$, IL-1 $\beta(B)$ or chicken $\beta$-actin $(C)$ probes. Lane 6, HPBMLT (negative control).

Cell lysates of fresh ATL cells and established ATL cell lines contained the LD78 protein. The expression of the LD78 gene might be correlated with the amounts of HTLV-1 produced, because SKT1-B cells expressed less amounts of HTLV-1 proteins than other HTLV-1-infected cell lines (Hattori, T., unpublished observations).

LD78 gene expression was abundant in monocytic leukemia cells, but the LD78 protein was not found in culture supernatants and cell lysates of these cells. The reason for the discrepancy between the Northern and Western blot analyses was not identified. In the $3^{\prime}$ untranslated region LD78 mRNA contains a (TATTTATT)n motif. Perhaps this motif is the site of interaction with a short half-life repressor (23) and is present in many cytokine genes. Interactions at this site with other cellular factors may change the stability of the mRNA. In other words, degradation of the LD78 mRNA in monocytic

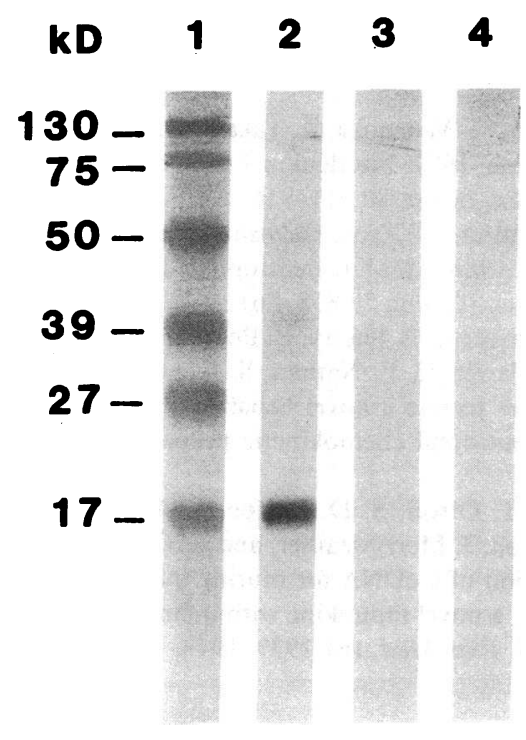

Figure 5. Specificity of the antibody OCT 801 examined by Western blot analysis. Lane 1 , molecular weight marker; lane 2, IL-2fused LD78 in $E$. coli; lane 3, IL-2 in E. coli; lane 4, pTM1 (control) in $E$. coli. The antibody was raised as described in Methods.
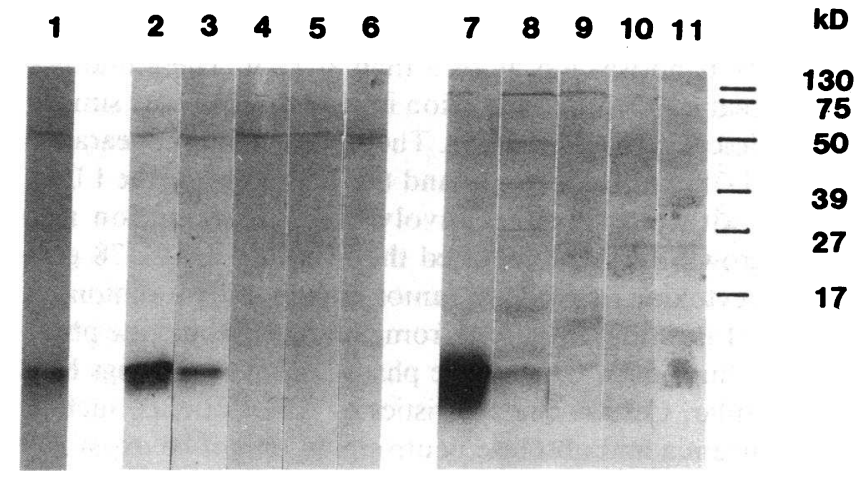

Figure 6. Western blot analysis of LD78 proteins from fresh leukemia cells and cell lines with the anti-LD78 antibody OCT801. $20 \mu \mathrm{l}$ of a cell lysate or cell supernatant was applied to each lane. Lane 1 , supernatant of COS-1 cells transfected with pcD-LD78 (positive control); lanes 2-6, cell supernatants; lanes 7-11, cell lysates; lanes 2 and 7, MJ; lanes 3 and 8, same as for lane 5 in Fig. 2; lanes 4 and 9 , HL-60; lanes 5 and 10, same as for lane 8 in Fig. 3; lanes 6 and 11 , HPB-ALL.

leukemia cells may be fast because ACT treatment decreased the amount of LD78 mRNA in HL-60 cells but not in MJ cells. In addition, the decrease in mRNA was not completely inhibited by treatment with CHX and ACT in HL-60 cells. A high amount of LD78 gene was induced when HL-60 cells were stimulated with LPS and PMA, and LD78 protein was detected in stimulated HL-60 cells. These results demonstrated that LD78 protein synthesis depended on the mRNA level of LD78 gene in certain conditions. Alternatively, degradation pathways of LD78 proteins might be different depending on the cell.

The kinetics of the induction of IL-1 $\beta$ and LD78 genes were closely associated in stimulated U937 cells. LD78 mRNA
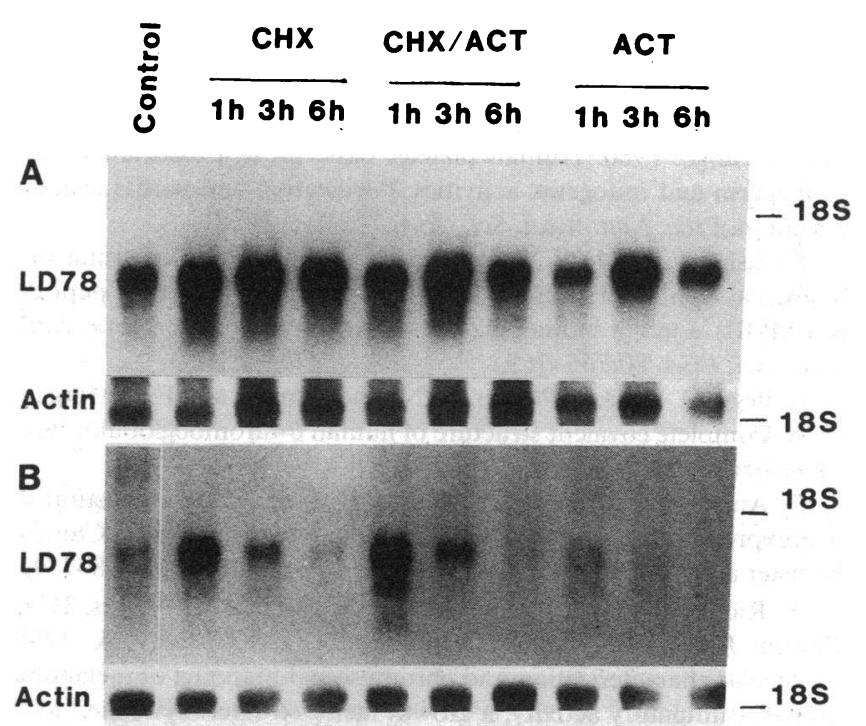

Figure 7. LD78 mRNA levels in MJ, HL-60 cells exposed to ACT, CHX, or a combination of these agents. MJ $(A)$ and HL-60 $(B)$ cells were exposed to ACT $(5 \mu \mathrm{g} / \mathrm{ml}), \mathrm{CHX}(10 \mu \mathrm{g} / \mathrm{ml})$, or a combination of these agents for the indicated times. $10 \mu \mathrm{g}$ of total cellular RNA was put in each lane and hybridized to the ${ }^{32}$ P-labeled LD78 cDNA or to a ${ }^{32} \mathrm{P}$-labeled chicken $\beta$-actin DNA probe. 
could be detected soon after stimulation began and the intensity of the band was less at $24 \mathrm{~h}$ than at $12 \mathrm{~h}$. These findings suggest that LD78 gene expression is regulated in a way similar to that described for IL-1 $\beta$ (23). The simultaneous appearance of the LD78 and IL-1 $\beta$ genes and the homology of the LD78 protein with other factors involved in inflammation and tumor growth further supported the idea that the LD78 protein is a cytokine involved in tumor growth, inflammation, or both. IL-1 is produced in cells from patients in the acute phase of ATL, but not in the chronic phase (24). The findings here were similar. Certain characteristics of ATL patients, such as hypercalcemia and absolute neutrophilia, might be explained by the production of these cytokines by ATL cells (25).

A macrophage inflammatory protein (MIP) has been isolated from mouse peritoneal macrophages stimulated with endotoxin (26). Human polymorphonuclear cells are chemokinetic to MIP, which also triggers hydrogen peroxide production. MIP and LD78 have $75.3 \%$ amino acid sequence similarity (27). These findings suggest that LD78 is a human counterpart of mouse MIP. Investigations are underway to define the biological activities of this cytokine.

\section{Acknowledgments}

This work was supported by a grant in aid for scientific research from the ministry of Education, Science, and Culture, Japan.

\section{References}

1. Obaru, K., M. Fukuda, S. Maeda, and K. Shimada. 1986. A cDNA clone used to study mRNA inducible in human tonsillar lymphocyte by a tumor promoter. J. Biochem. (Tokyo). 99:885-894.

2. Obaru, K., T. Hattori, Y. Yamamura, K. Takatsuki, H. Nomiyama, S. Maeda, and K. Shimada. 1989. A cDNA clone inducible in human tonsillar lymphocytes by a tumor promoter codes for a novel protein of the $\beta$-thromboglobulin superfamily. Mol. Immunol. 26:423-426.

3. Burd, P. R., G. J. Freeman, S. D. Wilson, M. Berman, R. DeKruyff, P. R. Billings, and M. E. Dorf. 1987. Cloning and characterization of a novel T cell activation gene. J. Immunol. 139:3126-3131.

4. Paul, D., S. Niewiarowski, K. G. Varma, B. Rucinski, S. Rucker, and E. Lange. 1980. Human platelet basic protein associated with antiheparin and mitogenic activities: Purification and partial characterization. Proc. Natl. Acad. Sci. USA. 77:5915-5918.

5. Castor, C. W., J. W. Miller, and D. A. Walz. 1983. Structural and biological characteristics of connective tissue activating peptide (CTAP-III), a major human platelet-derived growth factor. Proc. Natl. Acad. Sci. USA. 80:765-769.

6. Begg, G. S., D. S. Pepper, C. N. Chesterman, and F. J. Morgan. 1978. Complete covalent structure of human $\beta$-thromboglobulin. Biochemistry. 17:1739-1744.

7. Anisowicz, A., L. Bardwell, and R. Sager. 1987. Constitutive overexpression of a growth-regulated gene in transformed Chinese hamster and human cells. Proc. Natl. Acad. Sci. USA. 84:7188-7192.

8. Richmond, A., E. Balentien, H. G. Thomas, G. Flaggs, D. E. Barton, J. Spiess, R. Bordoni, U. Francke, and R. Derynck. 1988. Molecular characterization and chromosomal mapping of melanoma growth stimulatory activity, a growth factor structurally related to $\beta$ thromboglobulin. EMBO (Eur. Mol. Biol. Organ.) J. 7:2025-2033.

9. Luster, A. D., J. C. Unkeless, and J. V. Ravetch. 1985. $\gamma$-Interferon transcriptionally regulates an early-response gene containing homology to platelet proteins. Nature (Lond.). 315:672-676.

10. Walz, D. A., V. Y. Wu, R. D. Lamo, H. Dene, and L. E.
McCoy. 1977. Primary structure of human platelet factor 4. Thromb. Res. 11:893-898.

11. Sugano, S., M. Y. Stoeckle, and H. Hanafusa. 1987. Transformation by Rous sarcoma virus induces a novel gene with homology to a mitogenic platelet protein. Cell. 49:321-328.

12. Walz, A., P. Peveri, H. Aschauer, and M. Baggiolini. 1987. Purification and amino acid sequencing of NAF, a novel neutrophilactivating factor produced by monocytes. Biochem. Biophys. Res. Commun. 149:755-761.

13. Takatsuki, K., K. Yamaguchi, F. Kawano, T. Hattori, H. Nishimura, H. Tsuda, I. Sanada, K. Nakada, and Y. Itai. 1985. Clinical diversity in adult T-cell leukemia-lymphoma. Cancer Res. 45(Suppl):4644s-4645s.

14. Asou, N., M. Matsuoka, T. Hattori, F. Kawano, S. Maeda, K. Shimada, and K. Takatsuki. 1987. T cell gene rearrangements in hematologic neoplasms. Blood. 69:968-970.

15. Bennett, J. M., D. Catovsky, M. T. Daniel, G. Flandrin, D. A. G. Galton, H. R. Gralnick, and C. Sultan. 1976. Proposals for the classification of the acute leukemias: French-American-British (FAB) co-operative group. Br. J. Haematol. 33:451-458.

16. Bennett, J. M., D. Catovsky, M. T. Daniel, G. Flandrin, D. A. G. Galton, H. R. Gralnick, and C. Sultan. 1982. Proposals for the classification of the myelodysplastic syndromes. Br. J. Haematol. 51:189-199.

17. Shirono, K., T. Hattori, M. Matsuoka, S. Matsushita, N. Asou, and $\mathrm{K}$. Takatsuki. 1988. Adult $\mathrm{T}$ cell leukemia cell lines that originated from primary leukemic clones also had a defect of expression of CD3-T cell receptor complex. Leukemia (Baltimore). 2:728-733.

18. Maniatis, T., E. F. Fritsch, and J. Sambrook. 1982. Molecular Cloning: A Laboratory Manual. Cold Spring Harbor Laboratory, Cold Spring Harbor, NY. 545 pp.

19. Chirgwin, J. M., A. E. Przybyla, R. J. MacDonald, and W. J. Rutter. 1979. Isolation of biologically active ribonucleic acid from sources enriched in ribonuclease. Biochemistry. 18:5294-5299.

20. Feinberg, A. P., and B. Vogelstein. 1983. A technique for radiolabeling DNA restriction endonuclease fragments to high specific activity. Anal. Biochem. 132:6-13.

21. Sakai, K., T. Hattori, M. Matsuoka, N. Asou, S. Yamamoto, K. Sagawa, and K. Takatsuki. 1987. Autocrine stimulation of interleukin $1 \beta$ in acute myelogenous leukemia cells. J. Exp. Med. 166:1597-1602.

22. Lopata, M. A., D. W. Cleveland, and B. Sollner-Webb. 1984. High level transient expression of a chloramphenicol acetyl transferase gene by DEAE-dextran mediated DNA transfection coupled with a dimethyl sulfoxide or glycerol shock treatment. Nucleic Acids Res. 12:5707-5717.

23. Collart, M. A., D. Belin, J. D. Vassalli, S. D. Kossodo, and P. Vassalli. 1986. $\gamma$-Interferon enhances macrophage transcription of the tumor necrosis factor/cachectin, interleukin 1, and urokinase genes, which are controlled by short-lived repressors. J. Exp. Med. 164:2113-2118.

24. Wano, Y., T. Hattori, M. Matsuoka, K. Takatsuki, A. O. Chua, U. Gubler, and W. C. Greene. 1987. Interleukin 1 gene expression in adult T cell leukemia. J. Clin. Invest. 80:911-916.

25. Yamamoto, S., T. Hattori, N. Asou, H. Nishimura, F. Kawano, J. Yodoi, and K. Takatsuki. 1986. Absolute neutrophilia in adult T cell leukemia. Jpn. J. Cancer Res. (Gann). 77:858-861.

26. Wolpe, S. D., G. Davatelis, B. Sherry, B. Beutler, D. G. Hesse, H. T. Nguyen, L. L. Moldawer, C. F. Nathan, S. F. Lowry, and A. Cerami. 1988. Macrophages secrete a novel heparin-binding protein with inflammatory and neutrophil chemokinetic properties. J. Exp. Med. 167:570-581.

27. Davatelis, G., P. T. Olson, S. D. Wolpe, K. Hermsen, C. Luedke, C. Gallegos, D. Coit, J. Merryweather, and A. Cerami. 1988. Cloning and characterization of a cDNA for murine macrophage inflammatory protein (MIP), a novel monokine with inflammatory and chemokinetic properties. J. Exp. Med. 167:1939-1944. 